\title{
Journal of Experimental Food

\section{Editor's Note: Journal of Experimental Food Chemistry (Volume 2, Issue 3)}

\section{Mahendra Pal ${ }^{*}$}

Ex-Professor of Veterinary Public Health, College of Veterinary Medicine, Addis Ababa University, Debre Zeit, Ethiopia

*Corresponding author: Mahendra Pal, Ex-Professor of Veterinary Public Health, College of Veterinary Medicine, Addis Ababa University, Debre Zeit, Ethiopia, Tel: 091-9426085328; E-mail: palmahendra2@gmail.com

Received date: June 25, 2017; Accepted date: June 28, 2017; Published date: June 30, 2017

Copyright: (c) 2017 Pal M. This is an open-access article distributed under the terms of the Creative Commons Attribution License, which permits unrestricted use, distribution, and reproduction in any medium, provided the original author and source are credited.

Citation: Pal M (2017) Editor's Note: Journal of Experimental Food Chemistry (Volume 2, Issue 3). J Exp Food Chem 3: e109. doi:10.4172/2472-0542.1000e109

\section{Editorial Note}

Food chemistry envisages the major and minor components of food, their physiological, sensory, flavour, nutritional and microbiological aspects. The area of research comprised of bioactive constituents of foods such as phytochemicals, antioxidants and how products change while processing of food such as food additives, contaminants and putative health benefit molecules. Historically, experimental food chemistry began with early trials based on bread, milk and wine. The Volume 2 Issue 3 of the journal had published two research articles, one describes the flavour and aging of the wine, another is about pork sausage.

Oenology and viticulture are very ancient practices and words are derived from Greek. Untypical aging off flavour (UTA) in wine is considered as negative change in wine bouquet while storage, further leads to a considerable loss of wine quality. 2-Aminoacetophenone (AAP) is mainly responsible for the UTA, which gives odour taints such as 'furniture polish', 'wet wool', 'acacia blossom' or 'mothball' to the wine. The study of Horlacherhad tried to demonstrate the formation of AAP from Bacillus thuringiensis and to identify it as a possible reason for UTA appearance in wine. The findings indicated that the application of $B$. thuringiensis could not enhance the AAP formation, but concluded that it may be involved in aging process [1].

Chung and co-investigators [2] employed surface methodology to determine the effect and interactions of kkuaripepper powder and olive oil on physicochemical, textural and sensory properties of cooked pork sausage. The results revealed that the formulation for pork sausage with kkuaripepper powder and olive oil was $2.99 \mathrm{~g}$ and $9.12 \mathrm{~g}$, respectively, which was found to be optimum. These results could be very useful for the meat industry to increase the yield of sausages [2].

\section{References}

1. Horlacher N, Link K, Schwack W (2016) Bacillus thuringiensis Insecticides: Source of 2-Aminoacetophenone Formation in Wine? J Exp Food Chem 2: 113.

2. Chung M, Jung E, Joo N (2016) Kkuaripepper (Capsicum annum L.) and Olive Oil Effects on Quality Characteristics of Pork Sausage Studied by Response Surface Methodology. J Exp Food Chem 2: 114. 